\title{
Projetando para o daltonismo: o design instrucional como ferramenta para a construção de interfaces digitais mais inclusivas
}

\author{
Projecting for Color Blindness: instructional design as a tool to construct \\ more inclusive digital interfaces
}

\author{
Gabrielle Gonçalves de Freitas, Jéssica Santos Serrate, Laís de Souza Dias Ferreira, \\ Stefany Sivia Friedlander Raskin e Victor Kraide Corte Real
}

\begin{abstract}
daltonismo, comunicação visual, design universal, design instrucional
O daltonismo - anomalia visual caracterizada pela dificuldade de distinção entre determinadas cores -, embora possa ser um fator que comprometa a compreensão parcial ou total de uma peça visual, não é amplamente abordado durante o desenvolvimento de projetos em design. Considerando que grande parte das informações captadas pelo ser humano provém da visão e que muitas peças gráficas dependem da relação entre cores para evidenciar seus aspectos fundamentais, a existência de um ruído na comunicação com o público daltônico é praticamente certeira. O presente artigo se baseia nos princípios do Design Universal para evidenciar a necessidade de se desenvolver projetos considerando as limitações de possíveis usuários com discromatopsia, visando reconhecer e atender suas necessidades para que a comunicação aconteça de forma apropriada para todos os tipos de público.
\end{abstract}

color blindness, visual communication, universal design, instructional design

Color Blindness - a visual anomaly characterized by the difficulty in distinguishing certain colors —, while a factor that may compromise partial or total understanding of a graphic design, isn't widely covered in project design. Considering that a large part of the information captured by human being comes from our vision, and that many graphic pieces depend on the relationships between colors to highlight their own fundamental aspects, issues in communication with a colorblind audience is practically a given. This article uses the principles of Universal Design to highlight the need of considering the limitations of possible users with dyschromatopsia during the design process, aiming to recognize and meet their needs, so that communication can happen in an appropriate way for all kinds of people.

\section{Introdução}

Caracterizam-se como deficiências visuais o comprometimento óptico completo ou parcial de um ou ambos os olhos com a impossibilidade de serem corrigidas com o uso de lentes, tratamento clínico ou cirúrgico. Tais deficiências são divididas em dois grupos: cegueira e baixa visão (Almeida, 2014). Curitiba | Brazil | 2021 
Diferente da cegueira e da baixa visão, o daltonismo (também chamado de discromatopsia ou discromopsia) não é caracterizado como uma deficiência visual, mas como um distúrbio de percepção visual, causado pelo não funcionamento dos cones oculares. Cones oculares são células fotorreceptoras da retina, que recebem luz e a convertem em impulsos nervosos e possuem a função de diferenciar todas ou algumas cores. Dessa forma, problemas nessas células afetam a percepção de algumas ou todas as cores (Logvinenko, 2014).

O Design Universal considera que todos os produtos devem ser produzidos com o propósito de serem utilizados pelo maior número de pessoas possível, sem necessidade de adaptações, comunicando as informações aos usuários de modo eficiente, sem depender de suas habilidades sensoriais (Erlandson, 2008). Dentre as aptidões sensoriais, destaca-se aqui a visão, uma vez que muitas decisões tomadas em um projeto de design estão ligadas ao uso das cores.

O uso das cores é uma ferramenta eficaz para a transmissão de diversas informações por meio de códigos. No entanto, o daltonismo afeta a capacidade de identificar e/ou diferenciar matizes e tonalidades, tornando tais códigos difíceis de serem compreendidos pelos daltônicos (Jenny \& Kelso, 2007). Para eles, ações cotidianas que dependem da interpretação de códigos de cores tornam-se muito mais complexas, pois elas não são totalmente assimiladas.

Apesar dos daltônicos poderem se adaptar às suas limitações visuais e construir seus próprios repertórios em relação à teoria das cores - e serem influenciados pelas associações dos não portadores - , esses repertórios não são tão frequentemente estudados e nem pesquisados, havendo poucas referências sobre como daltônicos interpretam os significados das cores como informação em diferentes projetos.

Considerando essa escassez de estudos e os princípios do Design Universal, é evidente a importância de que o design atenda às necessidades de todos os indivíduos, inclusive os com discromopsia. Partindo disto, neste artigo serão apresentados métodos, por meio dos conceitos do design instrucional, que facilitem a comunicação de informações associadas às cores a daltônicos.

\section{Referencial Teórico}

\section{Teorias da Cor}

Leonardo Da Vinci, em escritos que hoje se encontram no livro "Tratado da Pintura e da Paisagem - Sombra e Luz" (2013/1651), afirma que a cor é uma propriedade da luz e não do objeto, sendo o preto visualizado quando algum objeto absorve toda a luz que o atinge, enquanto o branco é percebido quando há reflexão total das faixas de luz.

Posteriormente, o físico inglês Isaac Newton, no manuscrito Of Colors, foi o primeiro a associar a luz do Sol à existência das cores, a partir de um experimento que demonstrou o fenômeno da difração - a decomposição da luz solar em várias cores, como quando um raio de luz atravessa um prisma, formando um arco-íris. Esse conjunto de cores foi denominado espectro. 
O espectro é formado por sete cores: vermelho, laranja, amarelo, verde, azul, anil e violeta. Estas cores compõem a luz solar e formam o arco-íris. O círculo cromático, por sua vez, é uma representação em círculo das cores do espectro visível ao olho humano. Na maioria dos casos, ele contém doze cores diferentes - as primárias, secundárias e terciárias -, que auxiliam na composição de paletas para diversos projetos.

\section{Daltonismo}

O daltonismo é uma anomalia visual que se caracteriza pela incapacidade de diferenciação de determinadas cores e que atinge cerca de $10 \%$ da população mundial. Ele é comumente associado a fatores genéticos, mas pode também ser resultado de lesões nos órgãos responsáveis pela visão ou de origem neurológica (Frank et al., 2015).

Segundo Logvinenko (2014), a maioria das pessoas possui uma visão tricromática, formada por três tipos de cones sensíveis a comprimentos de onda curtos, médios e longos do espectro visível. Os daltônicos não possuem um dos tipos de célula cone. A partir disso, Fraser \& Banks (2007) classificam o daltonismo em três categorias, de acordo com o tipo de cone afetado ou ausente: a protanopia, em que os indivíduos são menos sensíveis aos comprimentos de onda longos, associados à percepção do vermelho; a deuteranopia, menor sensibilidade às ondas de comprimento mediano, responsáveis pela percepção do verde; e a tritanopia, que impossibilita a identificação de cores relativas a comprimentos de ondas mais curtos, como o azul.

Dentre os três tipos de daltonismo, o mais comum é a deuteranopia (dificuldade em identificar tons de verde e, por vezes, também de vermelho) que ocorre em cerca de $90 \%$ dos casos (Neiva, 2008). Considera-se que pessoas com visão tricromática podem identificar até 30.000 cores, enquanto um daltônico consegue identificar entre 500 a 800 cores apenas (Maia, 2013).

Tendo em vista que $80 \%$ das informações captadas pelo ser humano são visuais e que, destas, $40 \%$ resultam da percepção das cores, é evidente que o daltônico tem suas atividades diárias comprometidas ou prejudicadas, uma vez que apresenta dificuldade na percepção de contrastes, matizes e tonalidades das cores (Küppers, 1996).

\section{Acessibilidade}

A Norma Brasileira 9050/2004, define a acessibilidade como a possibilidade e condição de alcance, percepção, entendimento e utilização de edifícios, espaços urbanos e produtos com segurança e autonomia. Ou seja, acessibilidade é tornar esses espaços e produtos adequados ao uso de qualquer pessoa, independentemente de suas condições.

No meio digital, a acessibilidade pode ser entendida como a adequação para que qualquer usuário seja capaz de utilizar um sistema digital, sem que a interface do mesmo imponha obstáculos que dificultem ou limitem o seu uso (Barbosa \& Silva, 2010).

A acessibilidade neste meio representa, para o usuário, não apenas o direito de acessar uma rede de informações, mas também a eliminação de barreiras arquitetônicas, a 
disponibilidade de comunicação, o acesso físico a equipamentos e programas adequados e o acesso a conteúdos e apresentação da informação em formatos alternativos.

De acordo com o Ministério da Saúde do Governo Brasileiro (2017), na internet, a garantia da acessibilidade relaciona-se principalmente às recomendações do WCAG (Diretrizes de Acessibilidade para o Conteúdo da Web), que são parte de uma série de orientações para acessibilidade publicadas pela Web Accessibility Initiative do W3C e, no caso do Governo Brasileiro, pelo e-MAG (Modelo de Acessibilidade em Governo Eletrônico). O e-MAG está alinhado às recomendações internacionais, mas também estabelece outros padrões de acessibilidade para os sites governamentais.

Também há o apoio de OSCs, como, por exemplo, a da Acessibilidade Brasil, que promove acessibilidade digital, desenvolvendo ações que garantem o direito e acesso às tecnologias de informação e comunicação a pessoas que possuem alguma deficiência, segundo informações do portal Acessibilidade Brasil.

Produtos tornam-se acessíveis quando usuários com características diferentes podem utilizá-los sem a necessidade de modificações e/ou adaptações (Lidwell et al., 2011). Uma das ferramentas indispensáveis para tornar a acessibilidade real é a comunicação. Nesse sentido, quando utilizam-se cores para transmitir informações, as diferenças de percepção entre pessoas com e sem daltonismo devem ser consideradas nas peças de comunicação para facilitar a compreensão da informação.

\section{Design Universal}

O Design Universal (também chamado de Design Total ou Design Inclusivo) promove a ideia de projetar produtos, interfaces, serviços, ambientes e experiências cuja estética e usabilidade oferecidas possam ser utilizadas pelo maior número de pessoas possível, independentemente de habilidades ou capacidades motoras/físicas, idade, nacionalidade e outras especificidades, ou seja, abordando um design que seja para todos e qualquer um.

A expressão Design Universal (Universal Design em inglês) foi criada nos Estados Unidos, em 1985, pelo arquiteto Ron Mace, que influenciou as mudanças de padrões e referências para o desenvolvimento de projetos urbanos, de arquitetura e design. Para Mace, o Design Universal aplicado a um projeto consiste na criação de ambientes e produtos que possam ser usados por todas as pessoas, na sua máxima extensão (Ministério Público do Estado de São Paulo, 2010).

Na década de 1990, Ron Mace criou e conduziu um grupo multidisciplinar formado por arquitetos, engenheiros e designers, defensores de uma arquitetura e design mais centrados no ser humano e as diversidades intrínsecas a ele, para trabalhar no Center for Universal Design, da Universidade da Carolina do Norte, nos Estados Unidos.

O intuito do grupo era organizar e estabelecer critérios arquitetônicos e de design. O mote do projeto era considerar todas as possibilidades de uso pelos mais diversos tipos de pessoas, incluindo questões sociais, históricas, antropológicas, econômicas, políticas, tecnológicas e, principalmente, de ergonomia e usabilidade (Ministério Público do Estado de São Paulo, 2010). 
Esta equipe formulou os Sete Princípios do Design Universal, que funcionam como um guia para projetos inclusivos e passou a ser adotado mundialmente, principalmente em programas de acessibilidade plena. Os Sete Princípios de Design Universal são:

\section{$1^{\circ}$ Princípio: Uso equitativo}

O design deve ser útil e comercializável às pessoas com habilidades diversas.

Recomendações: Propor espaços, objetos e produtos que possam ser utilizados por usuários com capacidades diferentes, fornecendo os mesmos meios de utilização para todos: idênticos sempre que possível ou equivalentes quando não. Evitar segregação ou estigmatização de qualquer usuário. Promover igualdade de privacidade, segurança e proteção a todos. Desenvolver e fornecer produtos atraentes para todos os usuários.

\section{$2^{\circ}$ Princípio: Uso flexível}

O design deve acomodar uma ampla gama de habilidades e preferências individuais.

Recomendações: Criar ambientes ou sistemas construtivos que atendam às necessidades de usuários com diferentes habilidades e preferências diversificadas, admitindo adequações e transformações e oferecendo a possibilidade de escolha de métodos de utilização. Possibilitar adaptabilidade às necessidades do usuário, de forma que as dimensões dos ambientes e o manuseio dos produtos possam ser alterados. Possibilitar a precisão e acurácia do usuário. Oferecer a capacidade de adaptação ao ritmo do usuário.

\section{$3^{\circ}$ Princípio: Uso simples e intuitivo}

O uso do produto deve ser de fácil entendimento, independentemente da experiência, conhecimento, competências linguísticas ou nível de concentração do usuário.

Recomendações: Permitir fácil compreensão e apreensão do espaço/produto, independente da experiência do usuário, de seu grau de conhecimento, habilidades linguísticas ou nível de concentração. Acomodar uma ampla gama de competências linguísticas e de alfabetização. Eliminar complexidades desnecessárias e ser coerente com as expectativas e intuição do usuário. Disponibilizar as informações de acordo com a ordem de importância. Fornecer mensagens eficazes de aviso e de informação durante e após a conclusão da tarefa.

\section{$4^{\circ}$ Princípio: Informação de fácil percepção}

O produto deve comunicar ao usuário todas as informações necessárias de forma efetiva, independente de suas condições ambientais ou habilidades sensoriais.

Recomendações: Utilizar diferentes meios de comunicação, como símbolos, informações sonoras, táteis, entre outras, para a compreensão de usuários com dificuldade de audição, visão, cognição ou mesmo estrangeiros. Usar diferentes modos (pictórico, verbal, tátil) para apresentação redundante de informações fundamentais. Disponibilizar formas, objetos e imagens com contraste adequado, fornecendo uma diferenciação adequada entre informações essenciais e acessórias. Maximizar, com clareza e legibilidade, as principais informações. 
Diferenciar os elementos para que estes possam ser facilmente assimilados. Tornar fácil o uso do espaço ou equipamento. Fornecer compatibilidade com uma variedade de técnicas ou dispositivos utilizados por pessoas com limitações sensoriais.

\section{$5^{\circ}$ Princípio: Tolerância ao erro}

O design deve minimizar os riscos e as consequências adversas de ações acidentais ou não intencionais.

Recomendações: Considerar a segurança na concepção de ambientes e na escolha dos materiais de acabamento e demais produtos a serem utilizados, visando minimizar os riscos de acidentes. Organizar elementos para minimizar erros e riscos: os mais usados devem estar mais acessíveis; os perigosos eliminados, isolados ou blindados. Fornecer avisos quanto aos erros e aos riscos. Fornecer recursos à prova de erros. Evitar ações inconscientes em tarefas que exigem maior atenção e vigilância.

\section{$6^{\circ}$ Princípio: Baixo esforço físico}

O produto pode ser usado de forma eficiente e confortável, com o mínimo de esforço.

Recomendações: Dimensionar elementos e equipamentos para que estes sejam utilizados de maneira eficiente, segura, confortável e com o mínimo de fadiga. Minimizar ações repetitivas e esforços físicos que não podem ser evitados. Permitir que o usuário mantenha uma posição corporal neutra. Reduzir a força necessária para sua operação. Minimizar o esforço físico permanente.

\section{$7^{\circ}$ Princípio: Dimensão e espaço para acesso e uso}

Oferecer espaços e tamanhos apropriados para aproximação, acesso, manipulação e uso independentemente do tamanho do corpo, postura ou mobilidade do usuário.

Recomendações: Permitir acesso e uso confortáveis aos usuários, tanto sentados quanto em pé. Possibilitar uma linha de visão clara dos ambientes, elementos e produtos a todos os usuários, sentados ou em pé. Acomodar variações ergonômicas, oferecendo condições de manuseio, contato e alcance a usuários com as mais variadas dificuldades de manipulação, toque e pegada (acomodando variações de mão e punho). Possibilitar a utilização dos espaços por todos os usuários, de acordo com suas necessidades. Fornecer espaço adequado ao uso de dispositivos de auxílio ou assistência pessoal (The Center For Universal Design, 1997).

É importante lembrar que Design Universal, usabilidade e acessibilidade são coisas diferentes, mas com fronteiras que se perpassam. A acessibilidade se preocupa com a qualidade do acesso a qualquer pessoa; a usabilidade (uma vez garantido o acesso) estuda o perfil do usuário, a fim de propor a melhor qualidade de uso. O Design Universal, por sua vez, se preocupa em fazer com que o produto seja acessado e usado por qualquer um, respeitando seus 7 princípios. Um produto que possui design universal não precisa de adaptações ou ajustes para que um deficiente possa utilizá-lo (Alves, 2017). 


\section{Elementos metodológicos e desenvolvimento}

Para o desenvolvimento do presente artigo, utilizou-se o método de pesquisa exploratória, a partir de pesquisas bibliográficas e documentais (fontes secundárias), para reunir informações e dados que serviram de base para o entendimento do tema e, consequentemente, para a aplicação de uma proposta de ação projetual.

Com base nestas pesquisas, foram identificadas as necessidades e dificuldades daqueles que atuam na área do design gráfico, projetando para um público amplo, devido à escassez de projetos referenciais inclusivos.

A partir disso, como proposta para uma ação projetual, foi elaborado um manual - "A cor nos olhos de quem vê: Guia para projetos considerando o daltonismo" - , com o intuito de transmitir informações a respeito da criação de projetos inclusivos para daltônicos. Baseado no Design Universal, o guia procura evidenciar a importância de se desenvolver projetos considerando as possíveis limitações de usuários e de assegurar que a comunicação aconteça de forma apropriada para todos os tipos de público.

O uso exclusivo da cor é um dos principais problemas na hora de transmitir uma mensagem, pois nem todas as pessoas a percebem da mesma maneira, podendo tornar a mensagem ambígua. Assim, é importante que haja um bom contraste entre as cores, para garantir a legibilidade dos conteúdos, uma vez que $8 \%$ das pessoas do sexo masculino e $0,5 \%$ das pessoas do sexo feminino apresentam dificuldades em distinguir cores, principalmente as do espectro verde (Jenny \& Kelso, 2007).

Para assegurar que a informação no ambiente virtual seja visível a todos, é necessário escolher combinações de cores que possam ser facilmente distinguíveis também por usuários daltônicos e de baixa visão. Para tanto, é possível consultar aplicativos que simulam como estes usuários enxergam diferentes combinações.

Além disso, é importante que as imagens sejam acompanhadas por ícones ou legendas, tomando cuidado com a poluição visual, pois, para o daltônico, a dificuldade de legibilidade é maior (Connor, 2014).

O design editorial do manual buscou criar layouts atraentes, com otimização de espaço, adequação de contrastes e fontes tipográficas e a boa integração entre imagens e texto, visando ser também uma referência de projeto inclusivo e visualmente interessante, como visto na capa do manual e na página de sessão do índice (Figura 1). 
Figura 1 - Capa do Manual e ilustração da página de sessão do índice

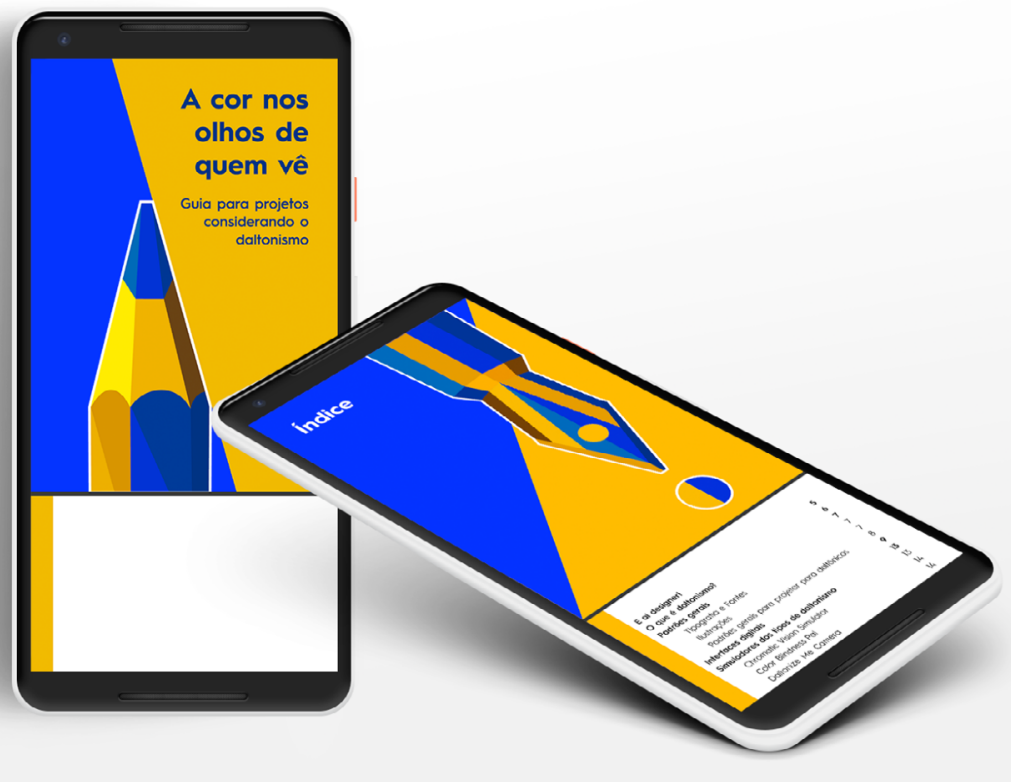

Para a elaboração do manual, foi utilizada a técnica de ilustração Low Poly (criação de imagens utilizando formas poligonais), em tons de azul e amarelo, visto que estas cores apresentam menor índice de distorção para daltônicos e que sua combinação gera bom contraste, auxiliando na percepção das diferentes variações de tons e contribuindo para a leiturabilidade das peças. Adicionalmente, foram utilizados contornos brancos nas figuras, para melhor diferenciação entre os elementos e o fundo, auxiliando o leitor a compreender a mensagem com maior facilidade.

O manual foi desenvolvido visando adequar-se a dispositivos digitais e mídia impressa, optando-se, assim, pela organização textual em apenas uma coluna para facilitar a leitura tanto em desktop quanto em mobile.

Como visto na Figura 2, a fonte tipográfica escolhida foi a Hurme Geometric Sans, uma fonte geométrica sem serifa e com caracteres bem definidos, foi utilizada em tamanho de 18 pontos, na cor preta, para ter o maior contraste com o fundo branco, possibilitando a leitura de modo eficiente e sem fadiga. Também foram utilizadas caixa alta e caixa baixa, para melhorar a diferenciação hierárquica do texto, sem depender apenas do uso de cores, e auxiliar a leitura em telas. 
Figura 2 - Diagramação do texto e exibição em página dupla

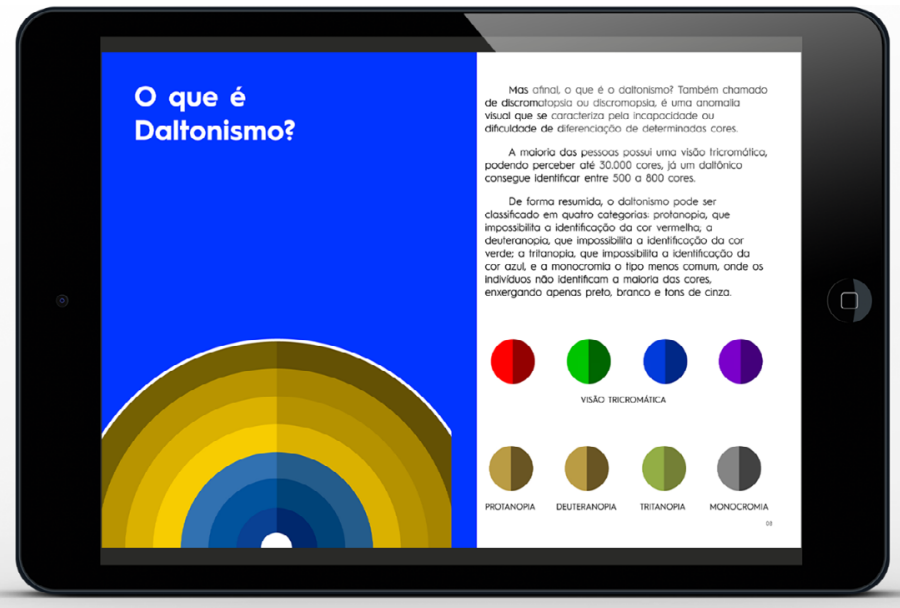

A organização entre os elementos gráficos e textuais segue uma hierarquia de informações, na qual é apresentado primeiro um texto explicativo e, em seguida, este é exemplificado com elementos gráficos e imagens.

Pictogramas contribuem para o entendimento do texto, fazendo com que a transmissão da mensagem não dependa apenas de variações de cor, tamanho, caixa alta e caixa baixa (texto). Além dos pictogramas, o uso de ícones, formas, imagens e outros elementos visuais facilitam a compreensão da mensagem.

As legendas, por sua vez, auxiliam na identificação dos pictogramas e, quando apresentadas em caixa alta, maximizam a legibilidade desta informação. A Figura 3 é um exemplo de bom uso de pictogramas e legendas.

Figura 3 - Diagramação de elementos e legendas

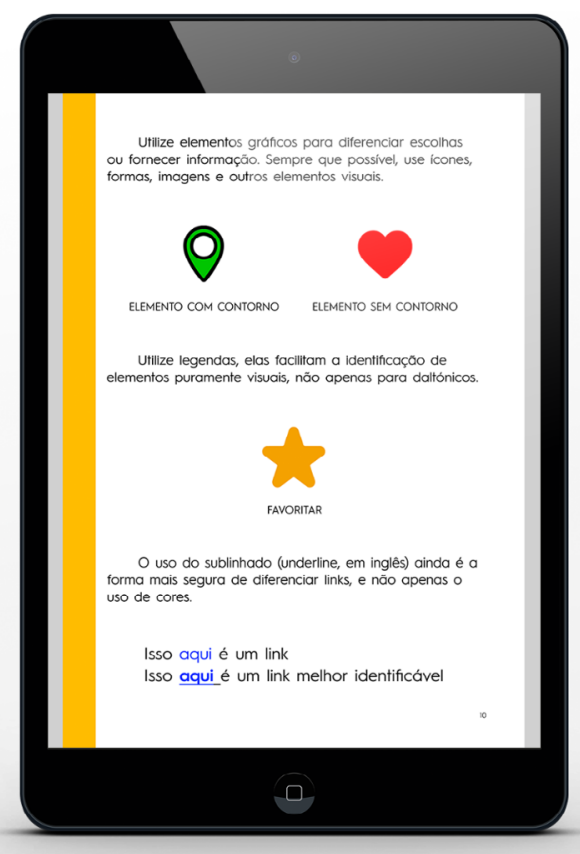


A partir de ferramentas que simulam a visão dos daltônicos (Chromatic Vision Simulator, Color Blindness Pal, Daltonize Me Camera, Color Binocular, Photoshop e Illustrator), foram elaboradas imagens que demonstram como estas ferramentas funcionam, visando estimular os leitores a utilizarem tais recursos. Como visto na figura 4, os títulos desses tópicos são apresentados com variação de peso, em semi-bold, destacando a hierarquia de informações.

Figura 4 - Diagramação de textos e imagens

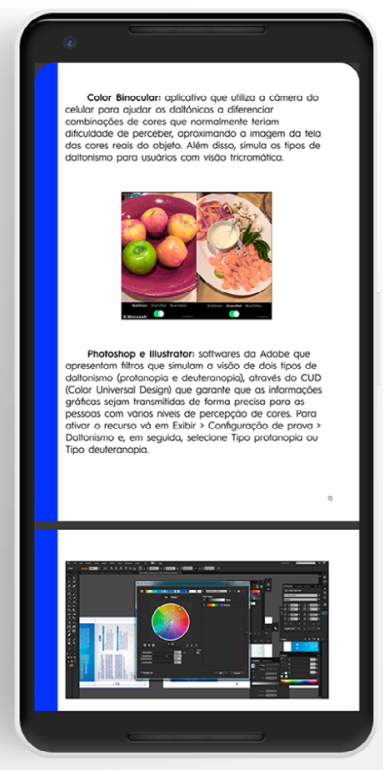

Também foram apresentados exemplos de modelos digitais inclusivos, desenvolvidos para facilitar a experiência dos daltônicos na interpretação de mensagens em espaços digitais, como na figura 5 .

Figura 5 - Diagramação de textos e imagens

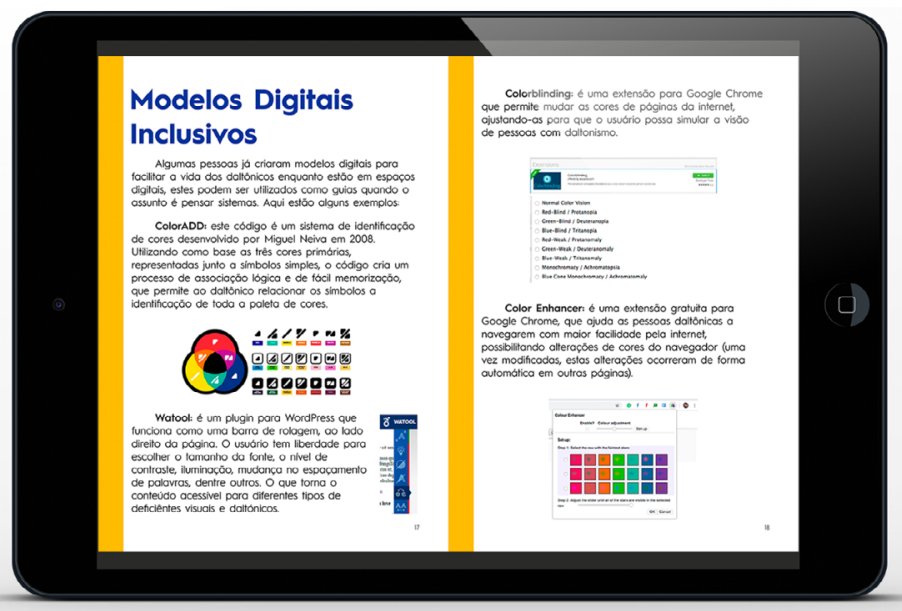


Este manual apresenta dicas para melhorar a experiência e compreensão das informações transmitidas no meio digital. Com ele, espera-se que mais projetos de design gráfico inclusivos à daltônicos sejam desenvolvidos.

\section{Considerações Finais}

Com o avanço da tecnologia, as cores se tornaram cada vez mais fundamentais na comunicação, sendo utilizadas para aumentar a eficiência de uma mensagem através do direcionamento da atenção ou para enfatizar uma informação (Farina et al., 2006 apud Neiva, 2008).

Ao considerarmos que aproximadamente $10 \%$ da população tem daltonismo, é inevitável que a assimilação total dessas mensagens seja prejudicada. Esse problema ocorre, em grande parte, porque um dos mecanismos básicos da percepção visual que é mais comprometido pela discromatopsia é a diferenciação entre figura e fundo, já que esta só acontece através da cor, seja por diferenças de matiz ou saturação (Arnheim, 2005 apud Souza \& Pereira, 2019).

Dessa forma, é primordial considerar a probabilidade de que alguma parcela do público de qualquer projeto visual seja daltônica. Portanto, é imprescindível dispor de ferramentas e procedimentos que minimizem o ruído na comunicação com estes usuários, evitando, assim, o seu desconforto visual e psicológico, além de potencializar o alcance da mensagem sendo comunicada.

Por vezes, a falta de projetos que atendam às necessidades dos daltônicos é explicada por designers como "falta de tempo, planejamento ou interesse do próprio cliente" (Maia \& Spinillo, 2012). Porém, ao evidenciarmos como a discromatopsia pode comprometer parcial ou totalmente a compreensão da informação - e levando em consideração os preceitos básicos do Design Universal - , faz-se necessário explorar as possibilidades de criação de projetos que possam atender a pessoas com discromatopsia tão bem quanto atendem ao público com visão tricromática - ou seja, atender a todo e qualquer usuário.

\section{Referências}

Acessibilidade Brasil. (2014). Uma ONG que trabalha pela acessibilidade. Disponível em http://www.acessibilidadebrasil.org.br/joomla/noticias/134-uma-ong-que-trabalha-pelaacessibilidade

Almeida, M. F. O. (2014) Conceitos e características da deficiência visual. Portal Educação. https://www.portaleducacao.com.br/conteudo/artigos/direito/deficiencia-visual-familiaescola/57025\#: :text=Caracter\%C3\%ADsticas\%20da\%20Defici\%C3\%AAncia\%20Visual\&te $\mathrm{xt}=$ caracteriza\%2Dse $\% 20$ por\%20perda\%20da,uso\%20de \%20lentes $\% 20 \mathrm{de} \% 20$ corre $\%$ C3\% A7\%C3\%A3o

Alves, A. V. (2017). Design Universal na Prática. Disponível em http://igti.com.br/blog/designuniversal/

Barbosa, S. D. J; Silva, B. S. S. (2010). Interação Humano-Computador. Rio de Janeiro: Elsevier. 
Connor, C. O'. (2014). Color Contrast And Why You Should Rethink It. Smashing Magazine. Disponível em https://www.smashingmagazine.com/2014/10/color-contrast-tips-and-toolsfor-accessibility/

Da Vinci, L. (2013). Tratado de Pintura - Leonardo Da Vinci - Preceitos da Pintura - Vol. 1. (F. Moraes, Trad.). São Paulo: Editora Criativo. (Obra original publicada em 1651)

Erlandson, R. F. (2008). Universal and accessible design for products, services, and processes. New York: Taylor \& Francis Group

Frank, . C. B. Junior; Oliveira, I. P.; Sales, Lanna; Spuza, Renata (2015). Signos de trânsito pelos portadores de daltonismo. Anais do $15^{\circ}$ Ergodesign \& Usihc [Blucher Design Proceedings, vol. 2, num. 1], 1414-1417. https://www.proceedings.blucher.com.br/articledetails/signos-de-trnsito-pelos-portadores-de-daltonismo-19089

Fraser, T. \& Banks, A. (2007). O guia completo da cor. São Paulo: Senac São Paulo.

Jenny, B. \& Kelso, N. V. (2007). Color design for the color vision impaired. Cartographic Perspectives. Number 57.

Küppers, H. (1996). Fundamentos de la teoria de los colores. México: Ediciones G. Gili.

Lidwell, W., Holden, K. \& Butler, J. (2011). Princípios Universais do Design. Porto Alegre: Bookman.

Logvinenko, A. D. (2014). On the colours dichromats see. Color Research \& Application. Vol. 39 , Issue 2.

Maia, A. F. D. V. M; Spinillo, C. G. (2012). O Papel Do Design Em Projetos Para Daltônicos. Conferência Internacional de Design, Engenharia e Gestão para a inovação Florianópolis: IDEMi 2012, Florianópolis.

Maia, A. F. D. V. M. (2013). Representação Gráfica de Mapas para Daltônicos: Um Estudo de Caso dos Mapas da Rede Integrada de Transporte de Curitiba. Disponivel em: https://acervodigital.ufpr.br/bitstream/handle/1884/29947/R\%20-\%20D\%20\%20AMANDA\%20FORTES\%20DALLA\%20VALLE\%20MAJO\%20DA\%20MAIA.pdf?sequen $\mathrm{ce}=1$

Ministério da Saúde. Governo Federal. (2017). Acessibilidade. Disponível em http://www.saude.gov.br/acessibilidade

Ministério Público do Estado de São Paulo. (2010). Desenho universal: e habitação de interesse social. Disponível em http://www.mpsp.mp.br/portal/page/portal/Cartilhas/manualdesenho-universal.pdf

Neiva, M. (2008) Sistema de Identificação de Cor para Daltônicos: Código Monocromático. Portugal: Universidade do Minho. Disponível em http://repositorium.sdum.uminho.pt/handle/1822/9191

Norma brasileira. (2004). Acessibilidade a edificações, mobiliário, espaços e equipamentos urbanos. Disponível em:

https://www.prefeitura.sp.gov.br/cidade/secretarias/upload/nbr_\%å2009050_acessibilidade\% 20\%202004\%20\%20acessibilidade_a_edificacoes_mobiliario_1259175853.pdf

The Center for Universal Design. North Carolina State University College of Design, (1997). The Principles of Universal Design. Disponível em https://projects.ncsu.edu/ncsu/design/cud/about_ud/udprinciples.htm 
The Newton Project. Cambridge Faculty of History. (2003). Of Colors. Disponível em http://www.newtonproject.ox.ac.uk/view/texts/normalized/NATP00004

\section{Sobre os autores}

Gabrielle G. Freitas, Bel. ${ }^{a}$, PUC Campinas, Brasil <gabrielle-freitas@hotmail.com> Jéssica S. Serrate, Bel. ${ }^{a}$, PUC Campinas, Brasil <jessicaserrate@gmail.com> Laís S. D. Ferreira, Bel. ${ }^{a}$, PUC Campinas, Brasil <laisdferreira@hotmail.com> Stefany S. F. Raskin, Bel. ${ }^{a}$, PUC Campinas, Brasil <stefanypepe@hotmail.com>

Victor K. Corte Real, Dr., USP, Brasil <victor.real@puc-campinas.edu.br> 
Apêndice - A cor nos olhos de quem vê: Guia para projetos considerando o daltonismo

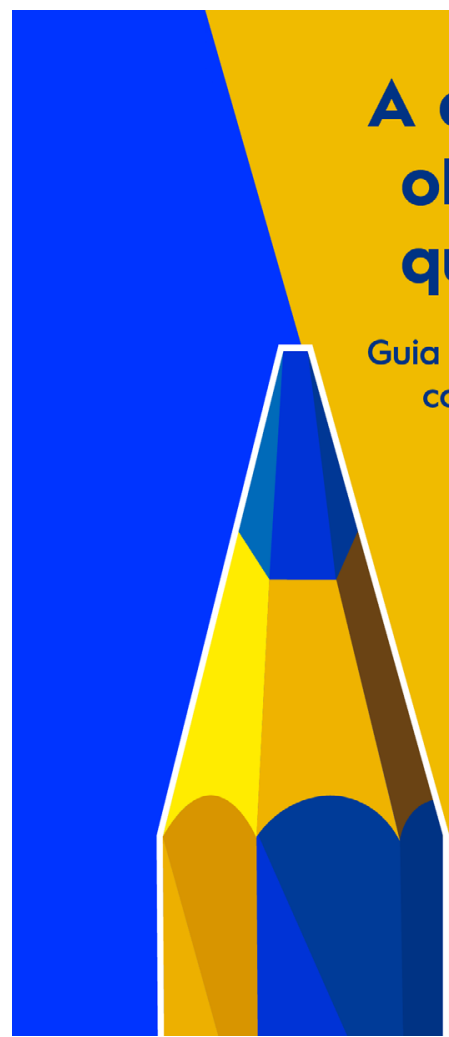

\section{A cor nos olhos de quem vê}

considerando o

daltonismo
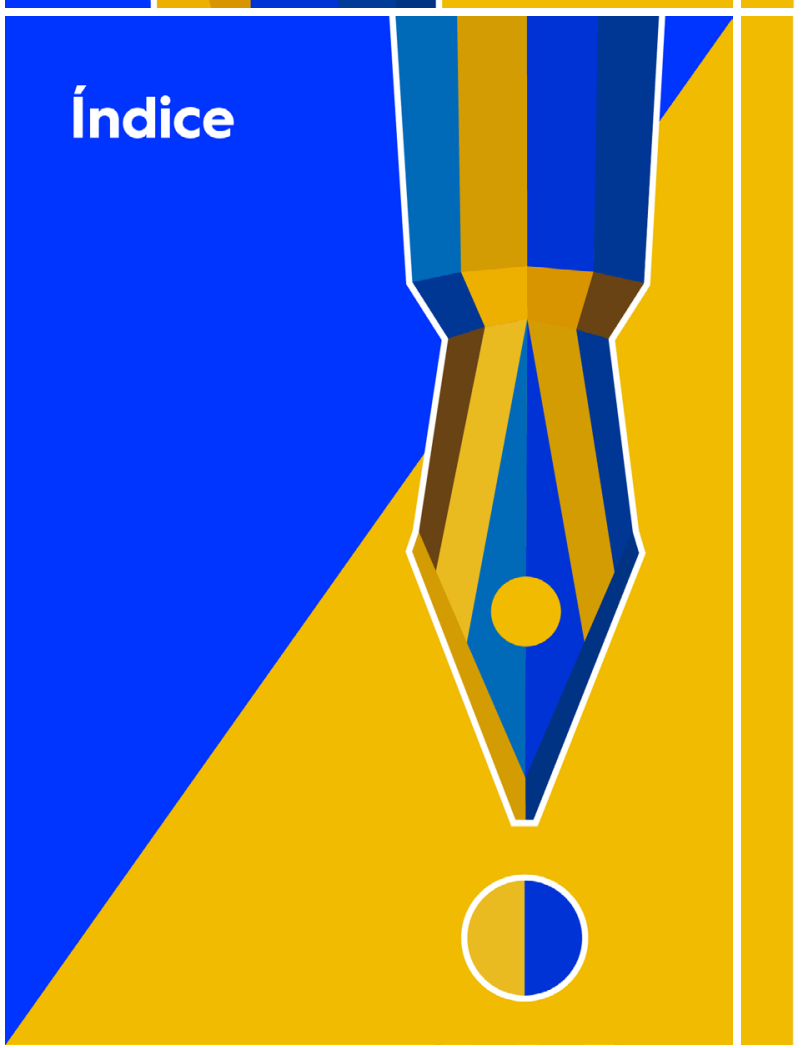

Este projeto foi desenvolvido na disciplina de Design

Instrucional do curso de Design Digital da PUC Campinas,

e tem como intuito transmitir informações a respeito da

criação de projetos em design inclusivos para daltônicos.

Gabrielle Freitas

Jéssica Serrate

Lais Ferreira

Stefany Raskin

\section{E ai designer!}

O que é daltonismo?

Padrões gerais

Tipografia e Fontes

|lustraçōes

Padrões gerais para projetar para daltônicos

Interfaces digitais

Simuladores dos tipos de daltonismo

Chromatic Vision Simulator

Color Blindness Pal

Daltonize Me Camera

Color Binocular

Photoshop e Illustrator

Modelos digitais inclusivos

ColorADD

Watool

Colorblinding

Color Enhancer

Referências 


\section{E ai, Designer!}

Você sabia que $10 \%$ da população mundial tem daltonismo? E que essa anomalia visual pode se manifestar de três formas diferentes?

Considerando que $40 \%$ das informações captadas pelo ser humano são resultantes da percepção das cores, e que o uso delas é uma das ferramentas mais utilizadas na transmissão de mensagens em um projeto em design, você já parou para pensar em como suas peças visuais atendem às necessidades do público que possui uma visão parcial das cores?

Este guia foi desenvolvido buscando apresentar soluções simples que possam ajudar no desenvolvimento de um design funcional, voltado não só ao público com visão tricromática, mas também à essa parcela da população que geralmente é desconsiderada durante os processos de criação.

\section{Padrões Gerais}

A maioria dos projetos em design utilizam recursos visuais como principal forma de comunicação, porém, no mundo, existem milhões de pessoas com daltonismo, baixa visão, visão subnormal, e perda parcial da visão (que precisam utilizar lentes de grau/aumento), por isso é importante considerarmos padrões mínimos que são confortáveis para o maior número de usuários possivel. Seguem aqui algumas recomendações para se projetar para a maioria dos usuários com problemas de visão:

\section{Tipografia \& Fontes}

Estas recomendações auxiliam a leitura confortável de títulos e corpos de textos, o que aumenta o entendimento do conteúdo escrito.

\section{Utilize:}

- Fontes com alta legibilidade, se possivel geométricas, bem definidas e com peso superior ao regular.

- Tamanhos entre 18 e 25 pontos, para materiais impressos.

- Fontes em caixa alta e caixa baixa para diferenciação do texto, em vez de cores texto.

- Entrelinhas entre $25 \%$ e $30 \%$ maior que o corpo do

- Parágrafos marcados pelo espaçamento antes da primeira palavra, e texto alinhado à esquerda.

- O maior contraste possível entre a cor da fonte e a cor do fundo, priorizando o uso do texto em cor preta sobre fundo em cor branca.

\section{O que é Daltonismo?}

Mas afinal, o que é o daltonismo? Também chamado de discromatopsia ou discromopsia, é uma anomalia visual que se caracteriza pela incapacidade ou dificuldade de diferenciação de determinadas cores.

A maioria das pessoas possui uma visão tricromática, podendo perceber até 30.000 cores, já um daltônico consegue identificar entre 500 a 800 cores.

De forma resumida, 0 daltonismo pode ser classificado em quatro categorias: protanopia, que impossibilita a identificação da cor vermelha; a deuteranopia, que impossibilita a identificação da cor verde; a tritanopia, que impossibilita a identificação da cor azul, e a monocromia o tipo menos comum, onde os individuos não identificam a maioria das cores, enxergando apenas preto, branco e tons de cinza.
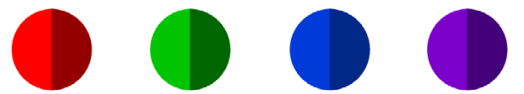

VISÃO TRICROMÁTICA
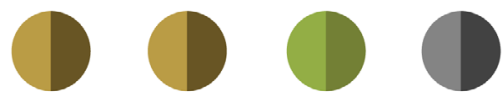

PROTANOPIA DEUTERANOPIA TRITANOPIA MONOCROMIA

Não Utilize:

- Palavras em itálico.

- Nunca diminua o espaçamento entre as letras e entre as palavras.

- Evite hifenização das palavras.

\section{llustrações}

Essas sugestões auxiliam na identificação dos elementos e associações de formas e cores dos objetos representados.

Utilize:

- llustrações simplificadas - abstrações podem gerar confusão.

- Traços espessos para diferenciar os elementos, entre si e do fundo.

- Cores contrastantes, com pouca variação de meios tons.

Não utilize:

Degrades e gradientes - a variação sutil de tonalidades é prejudicial na maioria dos elementos. - Texturas - em materiais impressos as texturas podem dificultar a percepção dos elementos e suas diferenciações com o fundo.

\section{Padrões gerais para projetar para daltônicos}

A identificação de elementos não deve se limitar exclusivamente a diferenciação de cores e/ou tonalidades, ou seja, a cor não deve ser a única forma de distinção entre os elementos. 


\section{Em interfaces Digitais:}

Utilize o maior contraste possivel entre cores, os daltônicos têm dificuldade em perceber as diferentes variações de luz e tonalidade. Além disso, 0 alto contraste é importante para garantir que haja boa leitura para vários usuários, não só os daltônicos.

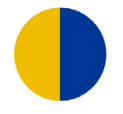

ALTO CONTRASTE

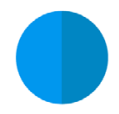

BAIXO CONTRASTE

A cor não deve ser o único indicativo de feedback, por exemplo, apenas o uso de vermelho ou verde como indicativo de "errado" e "certo" não é eficaz. Deve ser considerado o uso de ícones, microinterações e textos para sinalizar o erro ou sucesso.

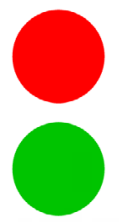

FEEDBACK RUIM

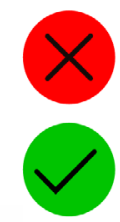

BOM FEEDBACK!

Evite utilizar gráficos de pizza, que são ruins para a maioria dos usuários, uma vez que a comparação entre as partes com cores distintas se torna difícil,

principalmente para os daltónicos. Para a apresentação de dados, o gráfico de barras é a melhor opção, pois é capaz de classificar as informações lado a lado, propiciando a sensação de estrutura e facilitando a compreensão

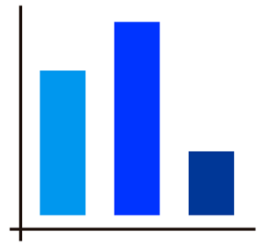

GRÁFICO DE BARRAS

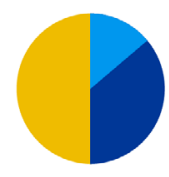

GRÁFICO DE PIZZA

Se a interface dispor de color picker (tabela para escolher a cor de um objeto ou produto), deve-se

adicionar legendas que destaquem ou complementam a cor do produto, não utilize apenas a cor para representar ela mesma.

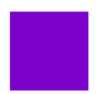

ROXO

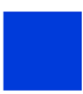

AZUL

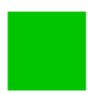

VERDE

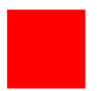

VERMELHO

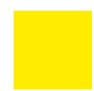

AMARELO
Utilize elementos gráficos para diferenciar escolhas ou fornecer informação. Sempre que possivel, use icones, formas, imagens e outros elementos visuais.

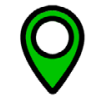

ELEMENTO COM CONTORNO

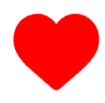

ELEMENTO SEM CONTORNO
Utilize legendas, elas facilitam a identificação de elementos puramente visuais, não apenas para daltónicos.

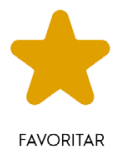

O uso do sublinhado (underline, em inglês) ainda é a forma mais segura de diferenciar links, e não apenas o uso de cores.

Isso aqui é um link

Isso aqui é um link melhor identificável

Diferencie e destaque elementos através da forma e do tamanho.

As vezes queremos dar destaque à determinadas coisas, mas você já percebeu como CAPS LOCK em bold GRITA POR ATENÇĀOI

Opte por utilizar diferentes tipos de sombra em vez de diferentes tipos de cores. Construir um design majoritariamente monocromático ajuda a diminuir a

frustração de pessoas com daltonismo, e facilita a criação de bons contrastes.

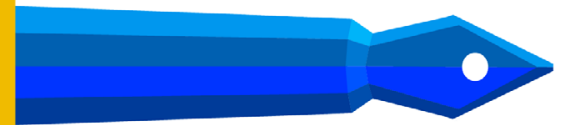

Utilize padrões ao invés de cores, ou seja, procure indicar através de grafismos qual é a diferença entre cada elemento.

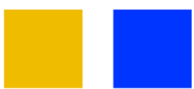

CORES

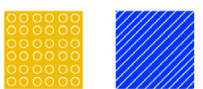

FORMAS E PADRÕES 


\section{Simuladores dos} tipos de daltonismo

Para haver uma maior inclusão social, é importante nos colocarmos no lugar do outro durante os processos de criação. Aqui estão alguns exemplos de ferramentas que simulam a visão dos daltônicos:

Chromatic Vision Simulator: este aplicativo permite visualizar as cores que os daltônicos dicromáticos

enxergam, em qualquer lugar, além de dar suporte aos que apresentam protanopia, deuteranopia e tritanopia.

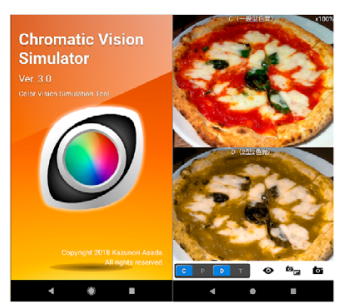

Color Binocular: aplicativo que utiliza a câmera do celular para ajudar os daltónicos a diferenciar combinações de cores que normalmente teriam dificuldade de perceber, aproximando a imagem da tela das cores reais do objeto. Além disso, simula os tipos de daltonismo para usuários com visão tricromática.

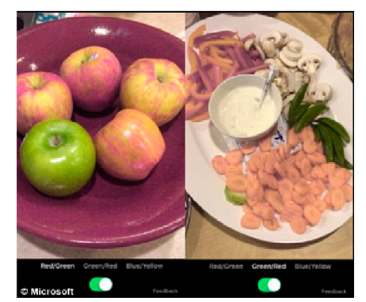

Photoshop e lllustrator: softwares da Adobe que apresentam filtros que simulam a visão de dois tipos de daltonismo (protanopia e deuteranopia), através do CUD (Color Universal Design) que garante que as informaçöes gráficas sejam transmitidas de forma precisa para as pessoas com vários níveis de percepção de cores. Para ativar o recurso vá em Exibir > Configuração de prova Daltonismo e, em seguida, selecione Tipo protanopia ou Tipo deuteranopia.

Color Blindness Pal: aplicativo que utiliza a câmera do celular para capturar as cores que o usuário deseja analisar em relação aos tipos de daltonismo, recebendo um relatório instantâneo e prático das cores e tonalidade enxergadas.

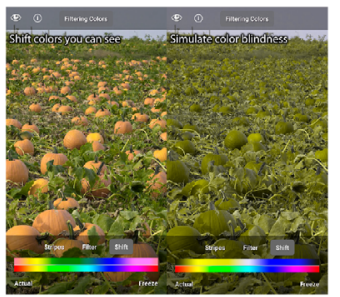

Daltonize Me Camera: aplicativo que simula a visão de três tipos de daltonismo (protanopia, deuteranopia tritanopia), a partir de filtros e em tempo real.
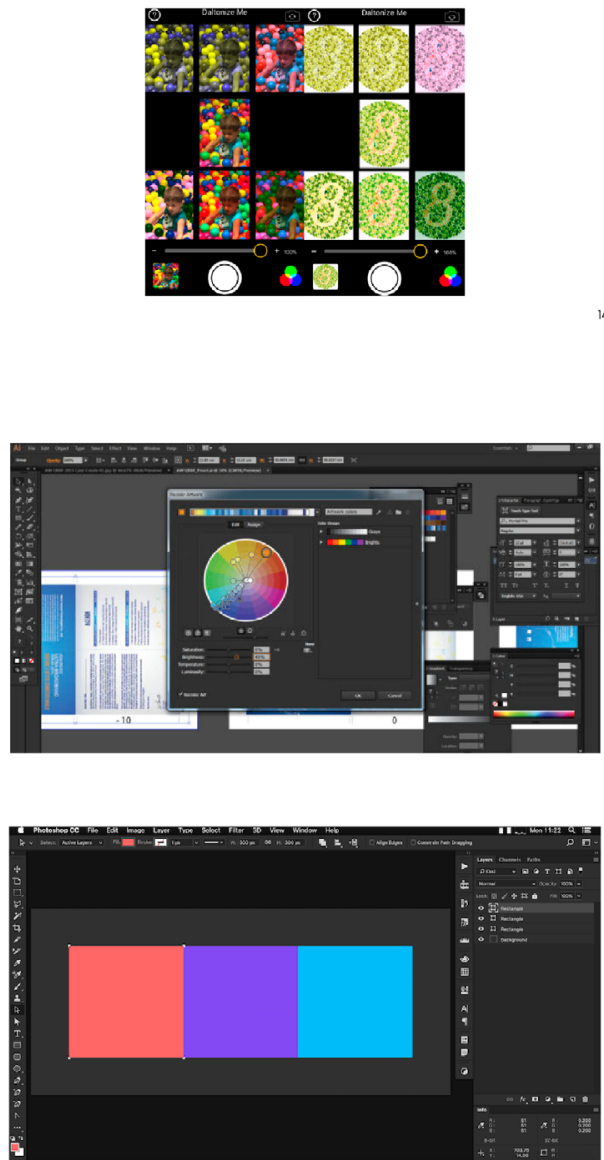


\section{Modelos Digitais Inclusivos}

Algumas pessoas já criaram modelos digitais para facilitar a vida dos daltônicos enquanto estão em espaços digitais, estes podem ser utilizados como guias quando o assunto é pensar sistemas. Aqui estão alguns exemplos:

ColorADD: este código é um sistema de identificação de cores desenvolvido por Miguel Neiva em 2008. Utilizando como base as três cores primárias, representadas junto a símbolos simples, o código cria um processo de associação lógica e de fácil memorização, que permite ao daltônico relacionar os símbolos a identificação de toda a paleta de cores.

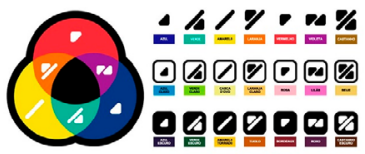

Watool: é um plugin para WordPress que funciona como uma barra de rolagem, ao lado direito da página. O usuário tem liberdade para escolher o tamanho da fonte, o nivel de

contraste, iluminação, mudança no espaçamento de palavras, dentre outros. O que torna o conteúdo acessivel para diferentes tipos de deficiêntes visuais e daltónicos.

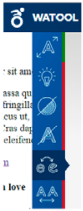

\section{Referências}

E aí, gostou? Quer saber mais sobre a importância e como desenvolver um design acessivel em seus projetos? Separamos algumas referências para que você possa se aprofundar no assunto.

Design acessivel: daltonismo e a cegueira dascores $\mathrm{http}: / / \mathrm{w} w \mathrm{w}$.acessibilidadelegal.com/13-daltonismo.php

O papel do design em projetos para daltônicos: https://www.academia.edu/2057184/O_Papel_do_Design _em_Projetos_para_Dalt\%C3\%B4nicos

Recoloração de web e conteúdos para daltónicos: https://repositorio.ipcb.pt/handle/10400.11/2111

Uso de simulação da visão de daltônicos no avaliação da informação cromática contida em embalagens:

https://www.infodesign.org.br/infodesign/article/view/ $689 / 395$
Colorblinding: é uma extensão para Google Chrome que permite mudar as cores de páginas da internet, ajustando-as para que o usuário possa simular a visão de pessoas com daltonismo.

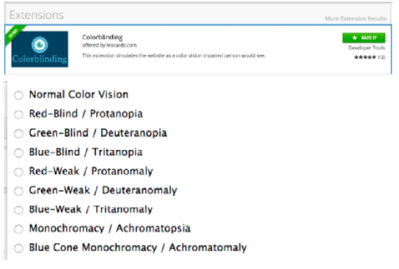

Color Enhancer: é uma extensão gratuita para Google Chrome que ajuda as pessoas daltônicas a navegarem com maior facilidade pela internet, possibilitando alterações de cores do navegador (uma vez modificadas, estas alteraçōes ocorreram de forma automática em outras páginas).
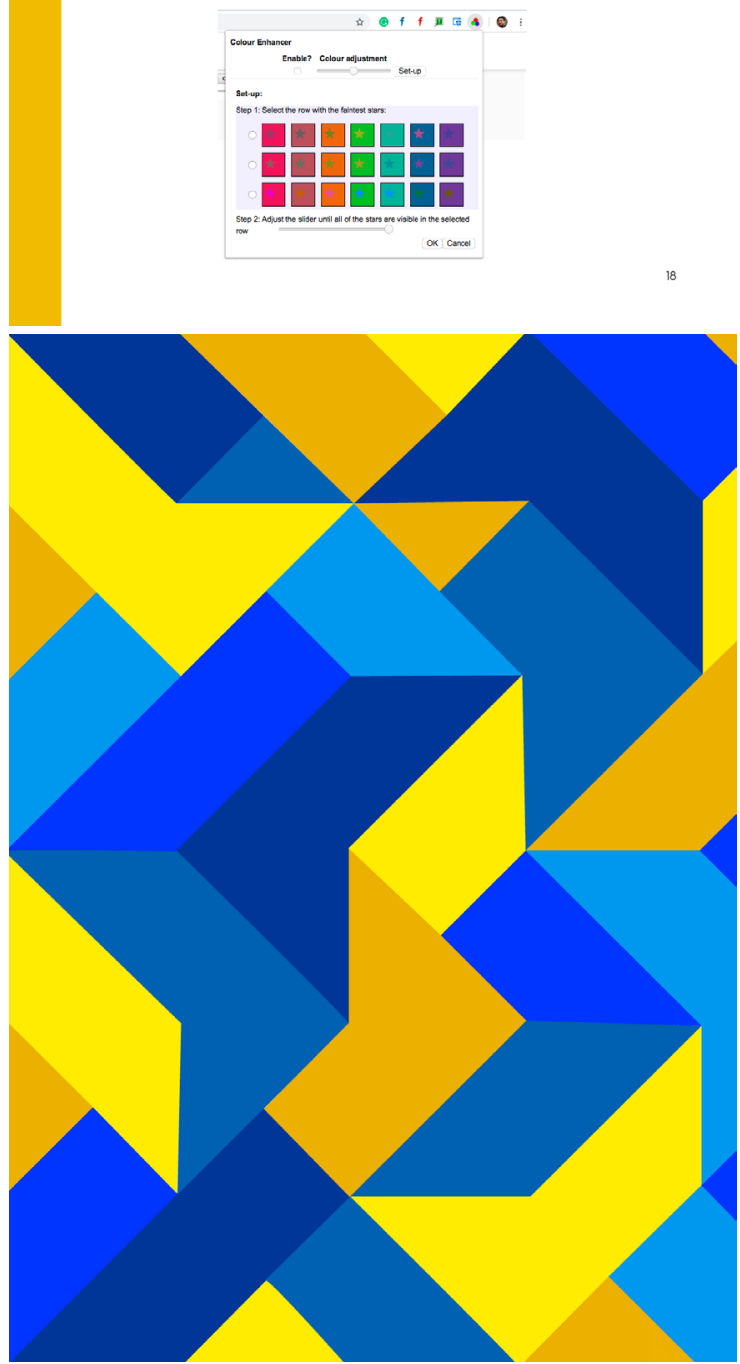